\title{
Media Portrayals of Transgender People in Pakistan - A Case of Misgendering and Marginalization
}

\author{
Jamil Asghar * Khurram Shahzad ${ }^{\dagger}$
}

\begin{abstract}
Stereotyping transgender people in media, all over the world, is more of a norm than an exception. Reviewing the Pakistani media archives, one gets the impression that, though over the past few decades some progress has been made, still there are many challenges to cope with in order to bring about a fairer and more balanced portrayal of the Pakistani transgender community. This paper investigates the media portrayals of the transgender people in Pakistan with reference to the Nation-one of the leading English newspapers. The study is both qualitative and quantitative, and analyzes the data stretched over five years-from 2011 to 2015. The researchers have demonstrated that there exists a highly patterned and repetitive stereotyping of transgender people verging on transphobic ostracization, misgendering and a thoroughgoing stigmatization. It has been demonstrated empirically and quantifiably as to how transgender people are bracketed with such criminal elements as prostitutes, drug addicts, human traffickers and pickpockets. Moreover, it has also been shown how they are consistently objectified and how their sexuality and criminality is foregrounded in such ways that it acquires the status of their only introduction. The paper emphasizes that in a country like Pakistan where the anti-transgender violence and stigmatization abound, it is important to get rid of clichd and formulaic representations of transgender people.
\end{abstract}

Keywords:: Transgender, representation, Pakistani media, transphobia, stereotypes.

\section{Introduction}

As all over the world, in Pakistan too, there is rampant transphobia in print as well as electronic media. Transphobia connotes a range of hostile behaviors and practices against transgender people (Eisner, 2013). Negative representation of transgender people in the Pakistani media is one of the many forms of discrimination which transgender people have to face routinely. Transgender people are often presented in highly essentialist and constructed images by media in Pakistan. As a whole, they face a great deal of prejudice in the society, and the present-day transgender representation in the Pakistani media is just reinforcing this legacy of negative stereotypes. The media depictions of transgender people not only inform the general public about the identity of this community, it also has important impact on the lived experience of the members of this community (Bockting, 2015).

In spite of the increasing visibility of the transgender community in media, there seems to be a serious lack of research on this issue. This article describes the main trends of

\footnotetext{
*Assistant Professor, Department of English, National University of Modern Languages, Islamabad.

E-mail: jasghar@numl.edu.pk

${ }^{\dagger}$ Assistant Professor, Department of English, National University of Modern Languages, Islamabad.
} 
transgender representation in the contemporary Pakistani print media with reference to one of the leading English newspapersthe Nation. The researchers have explored various social perspectives on the transgender characterizations built by some of the dominant media narratives in Pakistan.

The transgender narratives currently being circulated by the Pakistani media are considerably skewed and misleading as they tend to (re)present a truncated version of transgender identity. It is not uncommon in Pakistan to come across transgender constructs couched in Western frames and terminologies with transphobia embedded in them. In our times, there is an increased presence of transgender people in media but this increased presence is coming at a cost.

In recent years, the transgender portrayals in the Pakistani media have emerged as a subject of growing cultural and social attention. But the problem is whatever is being communicated by media with reference to this identity tends to be uncritically consumed by the society at large. This papers offers a critique of such monolithic media accounts and seeks to present the transgender identity in a nuanced and varied way, so that the living transgender experience could be accorded greater recognition. The paper also maps the way in which legal, cultural and social aspects of transgender identity are affected by the representations foregrounded by media.

The subcultural spaces allotted to transgender people by the media narratives are clearly demarcated from the locales reserved for males and females. This is a narrativity of ghettoization which seeks to exclude all those who do not fall into the dichotomous categories of male and female. This seems to be an interesting case of gender taking over humanity. In this perspective we are face-to-face with a social change which calls for a theoretical reflection which could enable us to re-conceptualize the identity and introduction of transgender people (Halberstam, 2005).

The term "transgender" is applied to individuals whose gender does not fit to the male/female normative categories. The term connotes behaviors which are at once biological, personal and cultural. The concept of transgender takes basic differentiations between the notions of gender, sex and sexual orientation for granted (Halberstam, 2005). Whereas gender is a cultural and social phenomenon, sex designates a biological category. There is no consensus about the transgender population in the world. However, estimates based upon the broad definition, have put the transgender population in the world at roughly 1 percent to 3.5 percent. More or less, the same ratio applies to Pakistan as well (Schwartz, Luyckx, \& Vignoles, 2011).

Transgender people exhibit a wide range of sexual, social and psychological traits like any human does. A considerable number to transgender people face gender dysphoria and a tiny minority get medical treatments e.g. psychotherapy, surgical sex-reassignment, hormone therapy, etc. Discrimination against transgender people is not uncommon. While accessing public accommodation, operating in the social sphere and seeking healthcare, they very often face discrimination, harassment and stereotyping (Hines, 2007). Against such issues, they are rarely provided with some sort of viable legal protection. 


\section{Literature Review}

We are living in a time when transgender people are routinely stereotyped and the clichd images of their identity and behavior are scattered all around us, thanks to the impact of a ubiquitous media. In Pakistan any discussion of transgender people is destined to descend into stigmatization and shaming. Talking openly on this topic is taken to be a cultural taboo and most of the discussion remains either derogatory or comical. To make matters worse, there is very little genuine research on this issue to fathom its seriousness and complexity. As per the comprehensive reviewing done by the researchers, the topic which the present paper seeks to investigate has not been explored by any researchers so far. However, there are certain adjacent issues which various people have researched from time to time. Here is a review of some of the notable researches done in this discipline.

Lisa M. Cuklanz and Sujata Moorti in their book Local Violence, Global Media: Feminist Analyses of Gendered Representations (2009) study the issue of gender representation. This book, though focuses on the international media treatment of gendered violence, devotes some discussion to the issue of transgender people in Pakistan. The book seeks to fill the gaps by furnishing a comprehensive range of present-day media representations of (trans)gender violence across a wide spectrum of social and geographic contexts.

Liz Miller in the article Queer is in the Eye of the Newcomer (2010) talks about, among other things, the "performance and place-based media" with regard to the issue of transgender identity. Miller mostly focuses on the LGBT issues. It has a cursory discussion on transgender people living not just in Pakistan but also in such countries as Turkey and Mexico. This article gives an account of two major media projects which worked with the groups of transgender people with refugee experiences in Canada to investigate some alternative media portrayals.

In 2011, Michael Waldman authored a book chapter titled Libraries and the Transgender Community. In this chapter, he gives a detailed account of the transgender narratives circulating mostly in the academia. The writer has given a brief account of some of the legal steps taken by Pakistan to grant recognition to the status of transgender people. The researchers points out: "Violence and discrimination certainly affect transgender people... When gender is policed to the extent that people are killed for transgressing gender rules, we all become a little more closed in, we lose a little freedom" (p. 27).

Cynthia Carter in the book chapter titled From Sex Role to Social Construction and Beyond (2012) is more concerned with the sex/gender dichotomy and the role of media. Pakistan is also included in the list of the countries surveyed by her. However, the chunk of discussion devoted to the Pakistani transgender community is quite sketchy. The tilt of the discussion is towards second-wave feminism and she challenges the lynchpin assumption that sex is biological, whereas gender is a social construct.

Asha P. Soman in the book chapter Penal Laws and Rights of Transgender (2013) deals with, as the title suggests, the penal laws and rights of transgender people. Though the lion's share of the study has been organized around the Section 377 of the Indian Penal Code 1860, it contains a few important aspects about the status and stereotyping of transgender people in Pakistan. This study is primarily legalistic in its scope and treatment of the subject. Soman begins her chapter with the following insightful words: "Gender 
issues always address two sections-men and women and the third category is often forgotten and that is the category of transgender people. Though this category does not demand any 'special' or 'additional rights', they are ostracized by the society and the government" (p. 276).

In an article titled Social Adjustment of Transgender: A study of District Chiniot, Punjab (Abbas, Nawaz, Ali, Hussain, \& Nawaz, 2014), the researchers take a general account of the problems faced by the transgender community of just one of the districts of PakistanChiniot. The study looks at the problems of the emotional adjustment of transgender people and how a tremendous lack of social integration can force such people into a living marred by existential and (inter) personal crises. However, this study fails to do justice with an extremely nuanced and demanding topic it purportedly deals with and most of the premises of the researchers are poorly grounded and most of the findings seem to be the researchers' own pre-conceived preferences and projections.

There is another study F. A. Khan (2014), in which the researchers have investigated the question of activism and transnationality with reference to the transgender community of Pakistan. This research also suffers from various methodical issues and, above all, its language disappoints the reader a lot. All in all, the researcher manages to bring about some workable suggestions and a few valuable insights.

Dickson and Sanders (2014) mainly focus on the constitutional discourses centered on the sexual orientations in three countries: India, Pakistan and Nepal. The study employs a qualitative methodology and a historicist approach. It is specifically useful for those who are interested in exploring legal issues associated with the affairs of transgender people.

Rizvi (2015), with a somewhat different set of preferences, pays attention to a slightly different yet related aspect, i.e. kidnapping of the children and 'transforming' them into transgender beggars. This 'transformation' is, to the researchers, at once social, psychological, discursive and institutional. People transformed this way are haunted by a lifelong identity crisis which is further complicated by their social and cultural stereotyping.

In an even more recent study, Redding (2016) has explored the issue of transgender rights in Pakistan. To the researchers, all the answers to the question of transgender rights are "multiple, layered and complex" (p. 7). In another extremely well-referenced study, A. M. Khan and Hashmi (2015) have taken into consideration various identity assumptions with reference to gender roles. However, it is astonishing to note that in such in extensive study, the researchers stop stop of taking a transgender perspective on identity.

Finally, mention must be made of Mamun, Heyden, and Yasser who authored a very insightful book chapter titled Transgender Individuals in Asian Islamic Countries: An Overview of Workplace Diversity and Inclusion Issues in Pakistan, Bangladesh, and Malaysia (2016). In this chapter, the researchers have been more concerned with the state of transgender people in Pakistan with reference to workplace diversity. The central premise of the study is: "In a society where gender roles are already askew, transgender individuals face particular challenges and such issues more often than not have been underemphasized in the diversity management literature" (p. 145). The chapter ends with a somewhat overly ambitious expectation when the researchers declare: "We develop a future research agenda for informing individuals, organizational leaders, and policy makers concerning transgender issues" (p. 146). 


\section{Research Methodology}

Research in the emerging discipline of gender studies gets all the more challenging when we take into account the comparatively recent problematization of the issue of transgender identity. Not too long ago has gender been re-conceptualized as a site of conflict and a locus of discursive discontents. All these moves regarding the question of (trans)gender have just added to the difficulty of the researchers in this domain. Keeping these considerations and difficulties in mind, the researchers have employed both qualitative as well as quantitative methods in this study and the following hypothesis has been sought to establish:

$H_{0}$ : Media portrayals of trangender people in Pakistan are stereotypical, biased and largely counterfactual.

The data for this research is mainly textual (news reports) which has been subjected to a rigorous content as well as thematic analysis. The researchers have also assessed the data quantitatively, wherever possible, and have calculated percentages and frequencies of transgender-related references and categorizations. This calculation has been underpinned by descriptive statistics. In this way, some of the notable findings/tendencies demonstrated by the data have been quantitatively mapped out on bar charts. These numeric and tabular techniques helped to make the study more objective and epistemologically more viable by triangulating the central assumptions laid down by the researchers.

The population of this research is the Pakistani print media, whereas the sampling is based upon the news reporting done by the Nation from 2011 to 2015. The Nation is one of the three leading English newspapers of Pakistan which has been published since 1986. It is owned by the Nawa-i-Waqt Group and published from the four cities: Islamabad, Karachi, Multan and Lahore. The Nawa-i-Waqt Group was founded by Hameed Nizami in 1940. The Nation has the third largest circulation among the Pakistani English dailiesestimated around 500,000 copies a day (Natarajan, 2017). The newspaper has fairly high level of coverage accuracy and editorial impartiality and all the stories/news items referred to in this study have been prepared either by investigative journalists or by the first-hand field reporters.

The researchers have used the purposive sampling technique with the explicit objective that it would help select the sample which is the most representative of the data. Having carried out a considerably exhaustive analysis of the data, the main findings have been presented which, in turn, led to the formulation of the recommendations.

\section{Data Analysis}

With regard to the data analysis, it is quite disturbing to note that the Pakistani print media mostly seems to be insistent on presenting the transgender narratives within the very frameworks and categories, the transgender community seeks to fight against. They are also excluded from the representations where it is most urgent for them to be present 
for the sake of accuracy in the face of a massive stereotyping. This is how the transgender stories and struggles are commodified on daily bases for a maximum commercial appeal.

All this is done in an exploitative and appropriative way. Most of the news reports the researchers came across in the course of this data analysis tended to stereotype transgender people and, more often than not, these 'constructed' images were foregrounded in naturalized terms. The most noticeable stereotyping is the way transgender people are routinely 'named' in the media. The very naming of them reveals much about the social attitudes towards this community.

It has been noted that most of the time transgender people are given derogatory names such as shemale, khusra, eunuch and so on. khawaja sara-a cultural euphemism with Sufi connotations and with slightly positive implications-is fast going out of currency and it is being replaced with overtly offensive words. But the problem is that most of the people in Pakistan, thanks to the lopsided media discourses, do not seem to even realize that such terms are offensive and make a regular use of them.

The following bar chart shows the frequency of the offensive names/terms used for transgender people. As can be seen from the chart, the most widely used term for people in the Nation from 2011 to 2015 is eunuch followed by even more derogatory terms such as shemale and khusra. Whereas the somewhat less controversial terms such as transgender and khawaja sara are very low on the frequency scale.

Figure 1

Naming the transgender community

\section{The way how transgender people are named}

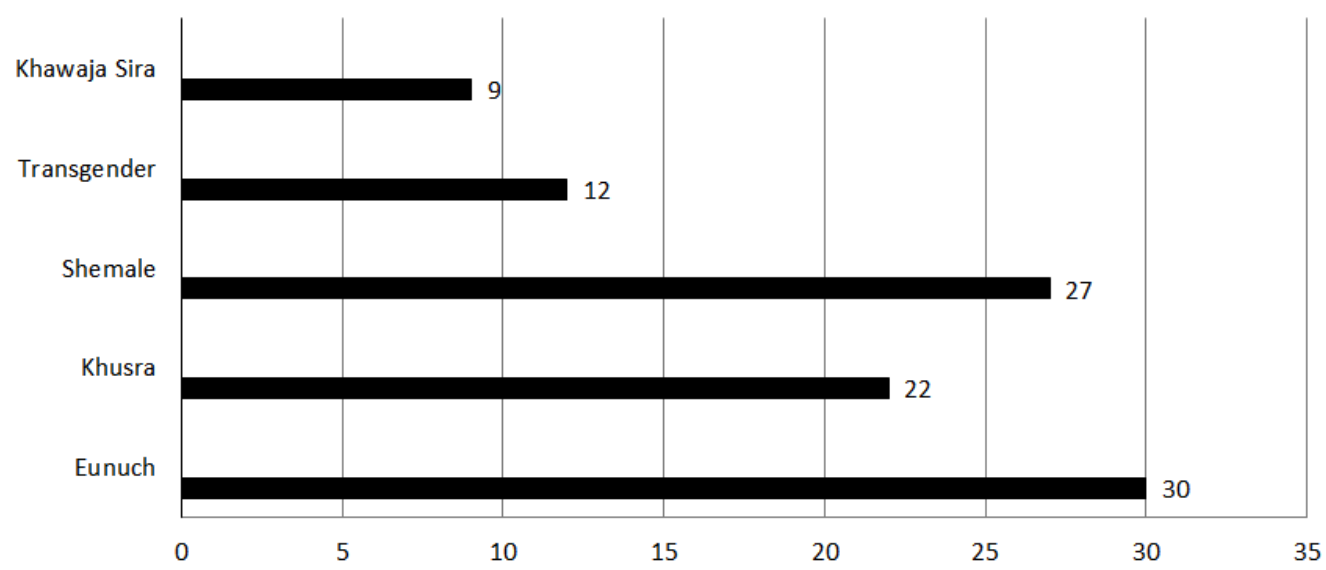

To begin with, the word "eunuch" has an altogether different meaning. It implies a person who has been castrated and here are its dictionary definitions:

- A man who has been castrated, especially (in the past) one employed to guard the women's living areas at an oriental court (Eunuch, 2000). 
- A castrated man, traditionally employed as a harem attendant or as a functionary in certain Asian courts (Eunuch, 2010).

It can be clearly understood by these definitions that terming a transgender person eunuch is a mischaracterization on technical grounds as well. Specifically, transgender females or transwomen do not fulfill the dictionary definition of eunuchs. Moreover, the word eunuch has quite derogatory connotations. All the renewed dictionaries have marked this word as offensive or derogatory (see Shorter Oxford English Dictionary (1993), (Merriam-Webster, 2004), Cambridge Advanced Learner's Dictionary (2008), etc.)

The next most widely used word on the frequency scale is shemale-another extremely offensive and misleading word with clear derogatory connotations. This word is so derogatory that the standard dictionary, both American and British, have not yet recorded it. What is termed as a shemale is, in fact, a male who has been feminized through a surgical procedure to act mostly in pornography industry. Castañeda and Campbell (2005) elaborate this term and its somewhat negative connotations:

The term shemale is mainly employed in the pornographic discourses to connote a trans woman with male sexual organs and effeminate characteristics. Many transgender people consider the word shemale as highly derogatory, contending that it evinces a disrespect towards the gender identity. It is also contended that employing the term shemale for a transwoman usually implies that she is either a prostitute or works in sex industry (p. 135).

It can be clearly seen that lumping all transgender people together under the rubric term shemale is culturally offensive and scientifically erroneous. The next commonly used word to describe transgender people is khusra-another notoriously pejorative term in the sociocultural milieu of Pakistan carrying a legacy of affront and derogation. Ironically, the words with the least offensive connotations-khawaja sara or transgender-has the lowest frequency.

Therefore, this analysis illustrates the deep-rooted derogation and pejoration associated with most of the terms used for transgender people. It shows the complexity which characterizes the semantics of transgender identity in Pakistan. This complexity can be assessed by going through the following first-hand opinion by Laxmi Narayan Tripathi, a renowned transgender rights activist and a well-known commentator on the topic of transgender identity:

In two sessions, transgender rights activist Laxmi Narayan Tripathi, author of Me Laxmi, Me Hijra, discussed intricacy of transgender identity and highlighted the painful experience of discrimination and abuse faced by transgender individuals. In the session titled ' $\mathrm{He}$, She, or ...' she rejected the words eunuch and shemale and argued these words are inadequate to describe the South Asian khawaja sara. She explained that while eunuch means a castrated man, shemale is a European word which reflects a conflict between gender identity and the assigned sex (Malik, 2015). 
Laxmi Narayan Tripathi is also critical of the Supreme Court of Pakistan for employing the "derogatory terms such as 'shemale"' (p. 8) in its 2009 verdict about the rights of transgender people. To Laximi, the need to break the spell of stereotypes and clichs is paramount as can be understood by the following except:

The Khawaja Saras are believed by many to be homosexuals and prostitutes who sell their bodies to earn money. There is indeed a drastic lack of knowledge with regards to what even the terms 'trans-sexual' and 'transgender' means (Omer, 2014).

Interestingly, the stigmatization of transgender people is not a historical phenomenon in the Subcontinent or the Indo-Pakistan culture. Historically, transgender people in Islamic tradition have been quite functioning members of the society and an unprecedented pejoration of their identity and their growing ostracization began with the arrival of the British colonizers. Laxmi Narayan describes how the advent of colonialism in the Subcontinent complicated the lives of transgender people:

...the word khawaja sara has Sufi connotations, as it means those who follow the way of the khawaja (master). Before the advent of Europeans in India, Hijras [a term used in South Asia to denote a transgender person] were trusted by society. They were soldiers, guardians of harems and advisors to kings but the Europeans could not understand them and drove them to the periphery of society (Malik, 2015).

Now let us move to the next segment of this data analysis which is about the stigmatization of transgender people in the media reporting (here, obviously, with reference to the Nation). The data demonstrates that most of the reporting about transgender people of Pakistan seeks to cast them into certain pre-conceived categories. One of the most persistent features the researchers noted was the routine bracketing of transgender people with criminals as if it were a norm. After the close and careful scrutiny of the data, there emerged a pattern which endorsed this observation of the researchers. The stigmatization and stereotyping of transgender people done by the Nation between 2011 and 2015 is being presented diagrammatically below:

This diagram depicts the reporting trends of the Nation regarding transgender people during 2011. During this year, a total of 93 news reports about transgender people were reported. Out of this total, $24 \%$ of the news reports either bracketed transgender people with prostitutes or right away declared them prostitutes. Next criminal category with which the transgender people were bracketed was those of drug addicts and $17 \%$ of the news reports lumped transgender people together with drug addicts. In 2011, only $4 \%$ of the news reports bracketed transgender people with pickpockets. Surprisingly, the same year, no news report grouped transgender people with human traffickers. This constituted an important observation for the researchers and when they further scrutinized the matter they came to know that during 2011 the crimes associated with human trafficking generally scored a low rate. Lastly, the trendline rising along the horizontal axis shows 
the largest percentage of neutral references. Interestingly, this percentage of neutral references is higher than all the percentages of various criminal categories put together.

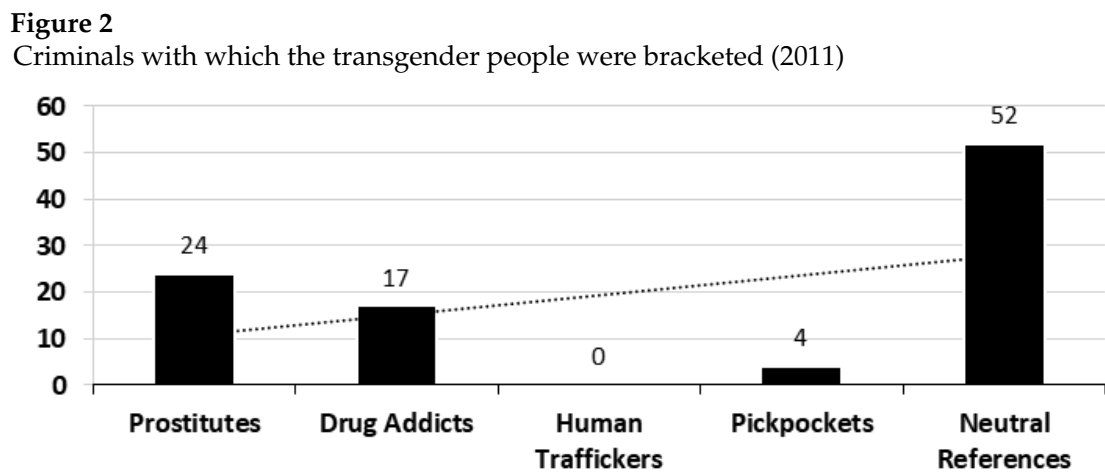

Criminals with which the transgender people were bracketed (2011)

Linear (Criminals with which the transgender people were bracketed

During the same year, while talking to a media person, Shabana, a trans woman, complain about the stigmatization of the transgender community by media in these words:

The negative projection of the hijra community in the media makes us rebellious. We really get hurt when people make fun of us and laugh at us because God made us the way we are. We also wish to participate in elections, be members of parliament, be a part of other decision-making authorities. We also desire to express ourselves on various platforms; we would love to be educated and develop ourselves and live the way other communities live in society (Inflation forcing eunuchs to begging, prostitution, 2012).

This data, when compared to 2011, illustrates a tremendous rise in the stereotyping trends prevalent in the reporting of transgender people. This tremendous rise is evidenced by the trendline which falls along the horizontal axis which is in opposition to the previous year. In 2012, as much as 52\% of the news reports right away grouped transgender people with prostitutes. Some of the news reports just termed all transgender people prostitutes. Similarly, a noticeable rise can be seen in the reports which sought to lump together all the transgender people with drug addicts and, as compared to 2011, this percentage has been around $9 \%$. Next, as much as 3\% of the news reports paired transgender people with human traffickers; however, there was no news report as regards the category of pickpockets is concerned. But, during 2012, the percentage of neutral references of transgender people came as down as $36 \%$. Here is a news item which typifies the main reporting trends of 2012:

RAWALPINDI - Criminal activities of eunuchs have reached alarming proportion in the area of Pir Wadhai with the connivance of police. The entire bus 
terminal has turned into a den of criminals and male prostitutes and gays. All the hotels are seething with the immoral activities of gays and eunuchs even in broad daylight. The eunuchs tempt the commuters with the seductive gestures to the dens of sins and sinners (Criminal activities of eunuchs on the rise, 2012).

\section{Figure 3}

Criminals with which the transgender people were bracketed (2012)
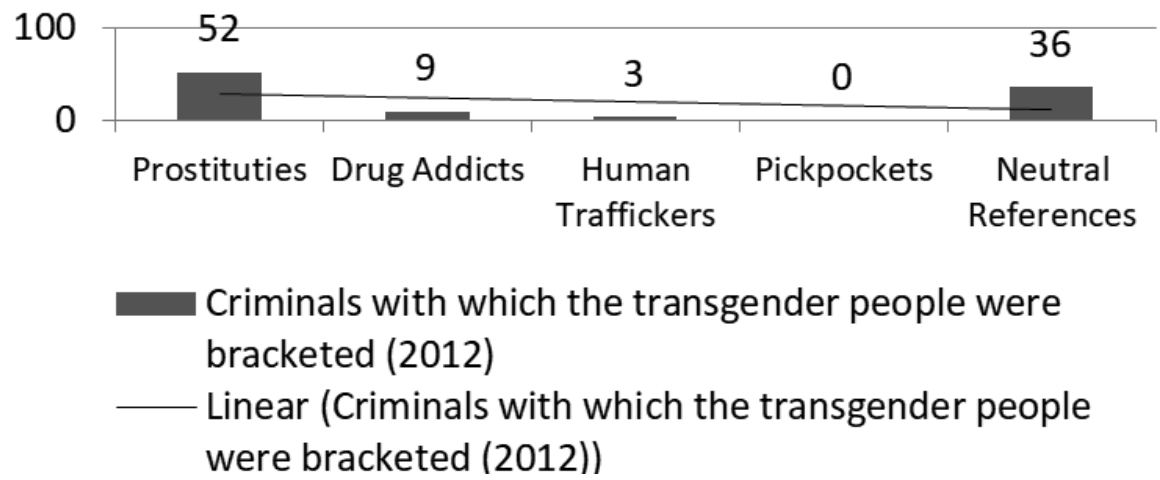

The most disconcerting aspect of this report is its heading: "Criminal activities of eunuchs on the rise". Look at this heading. It mischaracterizes transgender people in an extremely indiscriminate way. There may well be criminal elements within the transgender community of Pakistan but, even then, there is nothing unique about it. There are criminal elements in all kinds of communities in Pakistan as well as abroad. The mere presence, no matter how greater, of criminal elements in a community does not warrant an across-the-board stigmatization of that community. The headline could have managed to be less inflammatory and more balanced, had it been something like this: "Criminal activities of some of the transgender people on the rise". Such a headline would have been fairer as not all the members of transgender community are criminal.

Moreover, it is also worth noting as to how the narrative constructed by this news report foregrounds such words as "criminals", "male prostitutes", "gays", "broad daylight", "seductive gestures", "sins", "sinners", etc. The entire narrative is cast into highly moralizing and polemical terms. The irreducible impression a reader gets while going through this report is that there is a world of upright human beings who are, every now and then, tempted towards sinning and immorality by transgender people who are in toto given to debauchery, licentiousness and perversion. Let us proceed to next year.

The 2013 data shows some similarity with the 2011 data; however, there is not exact matching of course. This is indicated by the trendline which is rising along the horizontal axis. Moreover, the dominant reporting trends set off since 2011 continue. Even here prostitution remains the largest category assigned to transgender people and as much as $26 \%$ of the news reports lumped them together with prostitutes. About $10 \%$ of the reports bracketed transgender people with drug addicts and 6\% with human traffickers. About 
$3.3 \%$ of the news reports grouped transgender people with pickpockets. The remarkable feature of the 2013 data is the considerable percentage of the neutral references-55\%. Just like the 2011 data, the percentage of neutral references is higher than all the percentages of various criminal categories put together.

Figure 4

Criminals with which the transgender people were bracketed (2013)

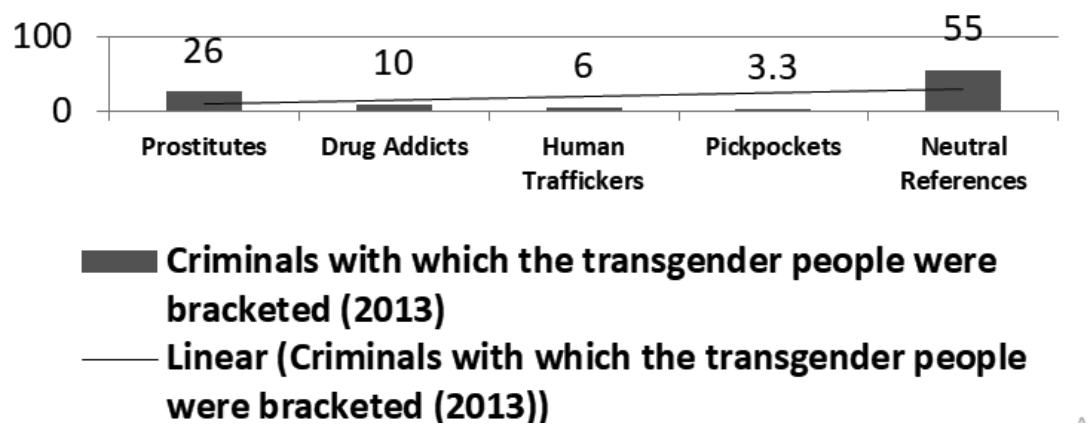

One noticeable reporting trend is to exoticize and otherize transgender people and their actions. Look at this news item which illustrates this trend:

KARACHI - Eunuchs also succumb to the temptation of getting into power, as two prominent members of their community have filed nomination forms for PS-115 and 130 Sindh (Two eunuchs also join electoral race, 2013).

Notice the word "also" in the first line which indicates the exoticization and otherization embedded in the reporting. Men and women routinely take part in election but our media does not exoticize them. But when it comes to transgender people, it becomes news. This shows that transgender people are taken as freaks, deviants and mutants. Many transgender people protest this kind of reporting and rightly demand that they should be taken "normally" like any other human being. Kami Sid, a renowned Pakistani transgender model, said:

We don't want to be looked at uniquely. That makes us think that we are perhaps eccentric. We demand humanity to be affirmed, not gender. Let us not think of gender in black and white terms. When we do something, it should be taken as a normal human activity and should not make news (Javed, 2012).

This bar chart presents the most dismaying data as criminal references with which transgender people are mentioned score the highest percentage of the five-year data collection/analysis period for this research. Equivalently, it scores lowest percentage with regard to the neutral reverences-just $24 \%$. As much as $63 \%$ of the news reports grouped transgender people with prostitutes. It is the highest percentage of this criminal category being associated with transgender people. The other criminal categories such as drug addiction, human trafficking and pickpocketing do not score much high and respectively 
stand at $6 \%, 4 \%$ and $3 \%$.

Figure 5

Criminals with which the transgender people were bracketed (2014)

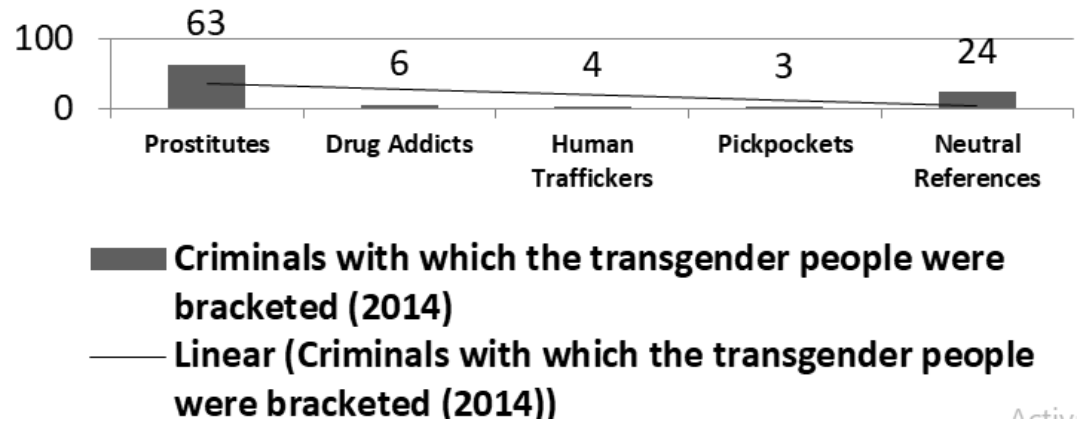

The trendline shows a steady fall along the horizontal axis. The following report characterizes these stigmatizing reporting trends:

Beggars, eunuchs, pocket pickers irk customers in markets- With the increase of customers in the prominent market of Rawalpindi, the numbers of beggars, eunuchs and young motorcyclists are too increasing augmenting the problems of purchasers. Beggars and eunuchs harass the shoppers in all the markets including Saddar, Commercial market, Raja Bazar and Westridge areas (Beggars, eunuchs, pocket pickers irk customers in markets, 2014).

Look at the headline. It reads like a series of indictment. The discourse built by this report presents transgender people as criminals of the deepest dye who are out to prey on the piety of men and women in the public sphere. Such editorial attitudes are deeply problematic. When a crime is committed by a transgender person, it should be communicated just as a crime committed by a man or a woman, i.e. not in an indiscriminate and generic way but in a nuanced and complex way. Lastly, the clear bracketing of transgender people with beggars and pickpockets can also be seen.

The bar chart shows the percentage of the news reports in which transgender people were bracketed with different criminals during 2015. All in all, there were 93 news reports about transgender people and out of this total, $42 \%$ of the news reports either straightaway called them prostitutes or at least bracketed with them. Similarly, $11 \%$ of the news reports lumped them together with drug addicts (including peddlers), 5\% with human traffickers, and $4.5 \%$ with pickpockets. It is not just a simple case of bracketing; rather, at times, they were just assigned these criminal categories. However, there were $38 \%$ neutral references which were void of any stereotyping and were largely fair enough to deal with the subject. But the neutral references are dwarfed when put in comparison to the total criminal references-almost $62 \%$ of the references made to transgender people are offensive. This bar chart also shows the frequency and rapidity with which transgender people are associated with prostitution. 


\section{Figure 6}

Criminals with which the transgender people were bracketed (2015)

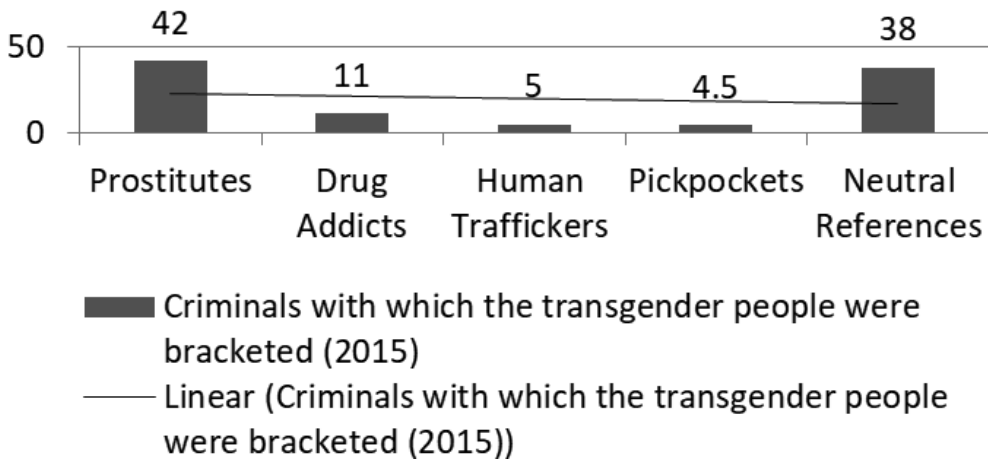

So much so that sometimes the word 'transgender' and 'prostitute' are used synonymously. Look at the following news item which is employing highly 'constructed' images of transgender community of Pakistan:

LAHORE - With dazzling make-up and stylish dresses, eunuchs roam across the provincial capital - from markets to parking and roads to residences. The more the society debates on their identity, the faster the eunuchs take to the streets for their rights. However, police officials found many eunuchs' involved in crimes, including prostitution, mugging, and drug pushing, but the lawmen are 'unable' to rein in (Javed, 2012).

This report paints the transgender picture with an extremely broad brush while failing to do justice with the nuances which characterize transgender people. Even headline given to this news item is extremely perfunctory: "Transactional eunuchs out". The headline gives this impression that as if all the transgender people moving around in the social sphere are "out" for certain untoward designs. The hyphenated word "transactional" is also subtly insinuating. It slyly whispers the idea that perhaps transgender people trade their bodies for monetary purposes, i.e. in a transactional way. Moreover, the pun in the word "transactional" is also offensive.

\section{Discussion and Findings}

The data presented and analyzed above enables us to bring out some findings which can be discussed here. It can be seen that most of the times, transgender people, when reported in media, have been associated with various criminals. The criminal category which scored highest and with which transgender people were associated is prostitution (overall 41\%). The criminal category which scored second highest and with which transgender people were associated is drug addiction (overall 10.5\%). Similarly, the criminal category which scored third highest and with which transgender people were associated is human trafficking (overall 6\%). Lastly, the criminal category which scored least and 
with which transgender people were associated is pickpocketing (Overall 2.5\%).What is more disturbing is the fact that the neutral references scored only $40 \%$. At the same time, in many cases, anti-transgender language, slurs, defamatory characterizations and general pejoratives were noted. It has also been noted that sometimes, psychopathic transwomen are shown as baby-stealers.

Moreover, transgender people were largely denied agency over the representations and framings of their stories and most of the narratives are tactfully selected, constructed and communicated by media. In preference to a more neutral term such as "transgender people", such offensive and technically flawed terms as "eunuch" "khusra" and "shemale" have been employed extravagantly. A vitriolic and essentialist bias operating in dichotomous terms exists not only in the reporting trends but also in the editorial attitudes.

\section{Conclusion}

This research makes it quite clear that there is an excessive amount of negative and stereotyped portrayal of transgender people in the Pakistani print media (here represented by the Nation, one of the leading English newspapers of Pakistan). The study also demonstrates that there exists an endemic problem with clichd and inaccurate media portrayals of transgender people which are at best misleading and at worst preposterous. Transgender people are routinely 'objectified' and their sexuality and criminality is foregrounded in such a way that it becomes the only remarkable introduction of the entire transgender community. All these inaccuracies and inadequacies of the media representations lead to much real life suffering on the part of the transgender community and for each stereotypical portrayal they have to pay a hefty price in terms of jeers, taunts, physical abuse and heartless violence. It is also plain from this research that the abundantly negative representation of the transgender people needs to be re-thought and re-assessed in more holistic and humanistic way. They are, obviously, human beings and their conduct is as good or bad as general human conduct is liable to be. The following comment by a transgender activist best rounds off this conclusion:

This society teaches its members to not even look at the faces of these mutants. So unless we change our attitude towards them, they will continue to suffer because they have a heart too. And like everyone else's heart; it hurts when it gets broken for a fault it did not commit (Ahmad, 2016).

\section{Recommendations}

On the basis of the data analysis, the researcher would like to advance certain recommendations which carry both policy as well as academic value. First and foremost, the media representations of the transgender people should be re-thought and should be nuanced, diverse and more humanistic. For this to happen, newspapers should revisit their role and should try to fight ignorance by improving the transgender depictions in their 
editorials and news reporting. Instead of disseminating an idealized and gentrified image of transgender people, newspapers should represent them with their complexity and authenticity. At the same time, there should be an increased liaison between the representatives of the print media and the transgender community aimed at securing the firsthand understanding. There should also be an increased liaison between the (print) media regulatory bodies and the transgender groups. Moreover, a new ethical code of practice for media should be designed to take into consideration the effect of inaccurate and/or prejudicial reporting on the transgender community. Lastly, transphobia should be combated with the same seriousness as racism and gender discrimination. 


\section{References}

Abbas, T., Nawaz, Y., Ali, M., Hussain, N., \& Nawaz, R. (2014). Social adjustment of transgender: A study of District Chiniot, Punjab (Pakistan). Academic Journal of Interdisciplinary Studies, 3(1), 61-71.

Ahmad, S. (2016). No country for a transgendered person. Daily Times. Retrieved December 25, 2016, from http://dailytimes.com.pk/opinion/02-Jun-16/no-country-for-a-transgenderperson.

Beggars, eunuchs, pocket pickers irk customers in markets. (2014). The Nation, p. 3. Retrieved December 13, 2016, from http://nation.com.pk/islamabad/06-Sep-2010/Beggarseunuchs-pocket-pickers-irk-customers-in-markets.

Bockting, W. (2015). Internalized transphobia. The international encyclopedia of human sexuality.

Castañeda, L., \& Campbell, S. (2005). News and sexuality: Media portraits of diversity. Sage Publications.

Criminal activities of eunuchs on the rise. (2012). The Nation.

Dickson, S., \& Sanders, S. (2014). Social difference and constitutionalism in Pan-Asia: Comparative constitutional law and policy. New York: Cambridge.

Eisner, S. (2013). Bi: Notes for a bisexual revolution. Seal Press.

Eunuch. (2000). In Oxford English dictionary (2nd ed.), Retrieved from https://en.oxforddictionaries.com/definition/eunuch.

Eunuch. (2010). In Webster's Third New International Dictionary, Retrieved from https://www.merriam-webster.com/dictionary/eunuch.

Halberstam, J. (2005). In a queer time and place: Transgender bodies, subcultural lives. NYU Press.

Hines, S. (2007). Transforming gender: Transgender practices of identity, intimacy and care. Policy Press.

Inflation forcing eunuchs to begging, prostitution. (2012). The Nation, p. 8. Retrieved December 14, 2016, from http://nation.com.pk/islamabad/23-Apr-2012/inflation-forcing-eunuchsto-begging-prostitution.

Javed, A. (2012). Transactional Eunuchs out. The Nation [Islamabad] 12 Dec. 2012: 6. Print.

Khan, A. M., \& Hashmi, R. S. (2015). Feminist assumptions and false promises of peace: A case study of India and Pakistan. Journal of Education E Social Sciences, 3(1), 198-208.

Khan, F. A. (2014). Khawajasira transgender activism and transnationality in Pakistan. South Asia in the World: An Introduction, New York: Routledge, 170-84.

Malik, S. (2015). ILF: Hijra to jirga. Dawn, Retrieved December 22, 2016, from http://www.dawn.com/news/1179534.

Merriam-Webster. (2004). Merriam-webster's collegiate dictionary.

Natarajan, S. (2017). Understanding the role of media in south asia. In Intercultural relations and ethnic conflict in asia (pp. 137-163). IGI Global.

Omer, M. (2014). The forgotten third gender in Pakistan. The Nation. 22, 2016, from http://nation.com.pk/sunday-plus/31-Aug-2014/the-forgotten-third-gender-in-pakistan.

Redding, J. A. (2016). Transgender rights in Pakistan?: Global, colonial, and islamic perspectives. 
Rizvi, A. J. (2015). Kidnapping of infants/young children and transforming/deforming them into prostitutes, pimps, beggars eunuchs \& transgender people and criminals who do not legally exist on the national computer database records.(the failure of democratic/civilian governments over period of several years) solutions for reducing/eliminating the criminal activities.

Schwartz, S. J., Luyckx, K., \& Vignoles, V. L. (2011). Handbook of identity theory and research. Springer.

Two eunuchs also join electoral race. (2013). The Nation, Retrieved December 13, 2016, from http://nation.com.pk/karachi/30-Mar-2013/two-eunuchs-also-join-electoral-race. 